\title{
Retraction Note to: Aberrant promoter methylation of the CHD1 gene may contribute to the pathogenesis of breast cancer: a meta-analysis
}

\author{
$\mathrm{Xi} \mathrm{Gu}^{1} \cdot$ Jin-Qi Xue ${ }^{2} \cdot \mathrm{Xi} \mathrm{Zhu}^{2} \cdot$ Ming-Shi Ye ${ }^{2} \cdot$ Wen-Hai Zhang ${ }^{2}$
}

Published online: 17 August 2015

(C) International Society of Oncology and BioMarkers (ISOBM) 2015

Retraction to: Tumor Biol. (2014) 35:9395-9404

DOI 10.1007/s13277-014-2235-Z

The Publisher and Editor retract this article in accordance with the recommendations of the Committee on Publication Ethics (COPE). After a thorough investigation we have strong reason to believe that the peer review process was compromised.

The online version of the original article can be found at http://doi.dx.org/ 10.1007/s13277-014-2235-z.

Wen-Hai Zhang

zhangwenhai401@126.com

1 Department of Breast Surgery, Shenging Hospital, China Medical University, Sanhao Street No. 36, Heping District, Shenyang 110004, People's Republic of China

2 Department of Breast Surgery, Shenging Hospital, China Medical University, Huaxiang Road No. 39, Tiexi District, Shenyang 110022, People's Republic of China 